www.jmscr.igmpublication.org

Index Copernicus Value: 79.54

ISSN (e)-2347-176x ISSN (p) 2455-0450

crossref DOI: https://dx.doi.org/10.18535/jmscr/v7i5.38

\title{
Role of Chemical Pleurodesis in management of Resistant Chylothorax following congenital cardiac surgery
}

\author{
Authors \\ Reyaz Ahmad Lone**1, Shadab Nabi Wani ${ }^{1}$, Peerzada Ommid Mohamad ${ }^{3}$, \\ Pradeep Bhaskar ${ }^{3}$, Ahmad bin Sallehuddin ${ }^{1}$, Aslam Faris ${ }^{3}$, \\ Muhammad Riyas K Rahmath ${ }^{2}$, Jiju John ${ }^{3}$, Faraz Masud ${ }^{2}$, Hesham Al-Saloos ${ }^{2}$, \\ Mohanad Mahmmod al-Qadi ${ }^{2}$, Akhlaque Nabi Bhat ${ }^{1}$ \\ ${ }^{1}$ Pediatric Cardiac Surgeon Hamad Medical Corporation \\ ${ }^{2}$ Pediatric Cardiologist Hamad Medical Corporation \\ ${ }^{3}$ Pediatric Cardiac Anesthesiologist Hamad Medical Corporation \\ Institution: Hamad Medical Corporation, Doha, Qatar \\ *Corresponding Author \\ Dr Reyaz Ahmad Lone \\ Consultant paediatric cardiac surgery \\ Email: rlone@hamad.qa \\ ${ }^{1}$ Cardiothoracic Department, Hamad Medical Corporation, Doha, Qatar
}

\begin{abstract}
Chylothorax in children is most commonly observed following the cardiac surgery for the congenital heart diseases. A number of therapeutic interventions have been used to reduce chylothorax production and promote resolution. Management involves supportive care, parenteral nutrition, octreotide infusion and if necessary chemical or surgical pleurodesis to obtain pleural adhesion, thus obliterating chylous leaks. We report herewith 3 children with refractory chylothoraces who improved significantly following pleurodesis using Povidone Iodine. Our findings suggest that this technique can be therapeutic for children with high flow chylothorax that fail to respond to conservative therapy.
\end{abstract}

Keywords: Chylothorax, Children, Cardiac Surgery, Chemical Pleurodesis, Povidone Iodine, Drainage.

\section{Introduction}

The incidence of chylothorax after congenital cardiac surgery has been reported between 2-6.6\% ${ }^{[1-3]}$ and is associated with substantial morbidity, mortality and a significantly longer length of hospital stay ${ }^{[1]}$. Conservative management involves chest tube drainage, dietary restrictions (medium chain triglyceride, parenteral nutrition) and use of octreotide in a staged protocol $^{[2,3]}$.
Presence of milky or creamy coloured pleural effusion is considered affirmative of chylothorax. Microscopic and biochemical analyses of the pleural effusion should show triglycerides $>1.2$ $\mathrm{mmol} / \mathrm{L}$ and cell count $>1000$ cell $/ \mu \mathrm{L}$ with a predominance of lymphocytes ${ }^{[4,5]}$.

The refractory cases do require surgical interventions in the form of pleurodesis, thoracic duct embolization and/or thoracic duct ligation, 
intrapleural fibrin glue and pleuroperitoneal shunts. We report herewith 3 children with refractory chylothoraces who improved significantly following pleurodesis using Povidone Iodine

\section{Case 1}

6 days old male child was diagnosed severe coarctation of aorta, aortic arch hypoplasia and moderated sized mid muscular Ventricular Septal Defect (VSD). He underwent surgical repair of VSD, resection of coarctation of the aorta and patch angioplasty of aortic arch. His postoperative course was complicated by chylothorax which was massive and required prolonged Pediatric Intensive Care Unit admission. He underwent bilateral pleurodesis on day 14 . The average drain was 192ml/day. Following chemical pleurodesis, the drain output reduced to an average of $3 \mathrm{ml} /$ day for the next 4 days. Subsequently, he developed chyloperitoneum which was managed conservatively. The chest tube was removed on $8^{\text {th }}$ post pleurodesis day and did not recur again. He is currently also been followed by endocrinologist for the thyroid function and is on replacement therapy with L-thyroxine.

\section{Case 2}

6 months old male patient underwent repair of Atrioventricular septal defect (AVSD) with Pulmonary Artery debanding. In the immediate postoperative period, patient developed bilateral chylothorax with average fluid output of $114 \mathrm{ml} /$ day. After failed initial conservative treatment, bilateral pleurodesis was performed and drainage decreased to $37 \mathrm{ml} /$ day for next 4 days and thereafter stopped on $6^{\text {th }}$ day. Thyroid function was normal. Hospital course was complicated by sternal wound infection and feeding difficulties which were managed by secondary wound closure and percutaneous endoscopic gastrostomy respectively.
Case 3

4 days old female baby diagnosed with Transposition of Great Arteries (TGA) following atrial balloon septostomy underwent Arterial Switch Operation (ASO).Post-operative course was complicated by high output chylothorax. Thrombosis of in nominate and superior venacava was noted in ultrasound doppler study of neck veins. Alteplase thrombolysis was done and subsequently patient was put on Low molecular weight heparin. After failed initial conservative methods, pleurodesis was done on day $20^{\text {th }}$. Average drainage was $245 \mathrm{ml} /$ day which decreased to average $57 \mathrm{ml} /$ day after pleurodesis and completely stopped on day 14. Subsequent follow up revealed normal thyroid function and the patient is healthy.

Table 1: Demographics of our patients and drainage following betadine pleurodesis

\begin{tabular}{|l|c|c|c|}
\hline Mean weight- 3.5 kg & Patient 1 & Patient 2 & Patient 3 \\
\hline Drainage days before PD & 14 & 20 & 19 \\
\hline Drainage days after PD & 4 & 6 & 14 \\
\hline Ave drain before PD & 192 & 114 & 245 \\
\hline Ave drain after PD & $\begin{array}{c}\text { reduced to 3 ml } \\
\text { in next 8 days }\end{array}$ & 37 & 57 \\
\hline
\end{tabular}

\section{Discussion}

Previously, chemical pleurodesis with talc, bleomycin, or tetracycline have been reported for chylothorax. ${ }^{2}$ However, the intrapleural injection of povidone-iodine as a chemical agent for pleurodesis in surgical chylothorax has been sparingly reported. Povidone iodine has previously been used for the sclerosis of postoperative pelvic lymphoceles ${ }^{[6,7]}$ and pleural lavage of empyema in adults. ${ }^{(8)}$ A $100 \%$ success rate has been reported when this agent was administered to 15 adult patients with a malignant pleural effusion ${ }^{[9]}$. In the pediatric age group, chylothorax following cardiac surgery for the congenital heart diseases is the most common cause $^{[10]}$. Chylothorax can also occur after obstruction in the superior vena cava without anatomic injury of lymph channels. Blalock et al. proved experimentally that occlusion of the superior vena cava (SVC) can produce 
chylothorax $^{[11,12]}$. Therefore, certain cardiovascular procedures like the Fontan operation are more prone to this complication due to the expected increase in SVC pressure. Ongoing losses cause compromise in the nutritional status and hence adequate calorie intake, protein supplementation and electrolyte balance are important modes in the management. Babies are at risk of sepsis as a result of loss of prothrombin, immunoglobulins, fibrinogen and lymphocytes. This complication has been on the rise in pediatric cardiac surgery, as observed in several reports ${ }^{[13]}$.

Pleurodesis (PD) is one way to obtain pleural adhesion, thus obliterating chylous leaks. Brissaud $\mathrm{O}$, et al reported that the chemical pleurodesis with povidine iodine was successful in three of the four neonates with congenital chylothorax ${ }^{[14]}$. They used $5 \mathrm{ml}$ to $10 \mathrm{ml}$ of either $4 \%$ povidine iodine scrub or $10 \%$ povidone iodine dermique. The duration of chest tube occlusion varied from 3 hours to 5 hours. In our series, we used $10 \mathrm{ml}$ of $4 \%$ povidine iodine through the pig tail catheters which was clamped for 3-5 hours during which the patient was monitored intensely. Mitanchez et al reported the use of $4 \%$ povidone iodine for congenital chylothorax which was successful however the infant developed renal failure subsequently ${ }^{[15]}$. With the advent of aggressive initiation of non-operative management, the number of surgical procedures have decreased resulting in improving mortality rate from $50 \%$ before 1950's to 10-20\% currently.

We decided to administer intrapleural povidoneiodine when surgical abrasion of the pleura was being considered. This method requires general anaesthesia, with associated risks of adverse effects such as blood loss and pain. Previously, chemical pleurodesis with talc, bleomycin, or tetracycline has been performed in chylothorax ${ }^{[16]}$. The administration of either topical povidone iodine applications or the iodine-based contrast agents may lead to transient thyroid dysfunction, especially in infants ${ }^{[21]}$. Excess iodides may also induce thyrotoxicosis in susceptible individuals
[22]. The mechanism of pleurodetic effect of povidine iodine is unknown. It may due to the low $\mathrm{pH}$ (2.97) of the sclerosing solution ${ }^{[23]}$. Iodine has strong oxidative and cytotoxic properties which induce a potent inflammatory response in the wall of any fluid-containing structure ${ }^{[4]}$. Povidoneiodine also has anti exudative properties related to the chelation of proteins ${ }^{[6]}$.

Olivares-Torres et al. reported two patients and neither of them presented signs or symptoms of hyperthyroidism, although they repeated povidine iodine pleurodesis second time to the patient in whom it was unsuccessful in the first instance ${ }^{[23]}$.

We found this method of pleurodesis to be quiet effective and recommend more extensive research on a larger subset of patients.

Its early use may avoid more aggressive approaches such as thoracic duct embolization and surgical interventions.

\section{Bibliography}

1. Mery, C.M., et al., Incidence and treatment of chylothorax after cardiac surgery in children: analysis of a large multiinstitution database. $\mathrm{J}$ Thorac Cardiovasc Surg, 2014. 147(2): p. 678-86 e1; discussion 685-6.

2. Cormack, B.E., et al., Use of Monogen for pediatric postoperative chylothorax. Ann Thorac Surg, 2004. 77(1): p. 301-5.

3. Panthongviriyakul, C. and J.E. Bines, Post-operative chylothorax in children: an evidence-based management algorithm. J Paediatr Child Health, 2008. 44(12): p. 716-21.

4. Staats BA, Ellefson RD, Budahn LL, et al: The lipoprotein profile of chylous and nonchylous pleural effusions.Mayo Clin Proc 1980;55:700-704.

5. Straaten van HL, Gerards LJ, Krediet TG: Chylothorax in the neonatal period. Eur $\mathbf{J}$ Pediatr 1993;152:2-5.

6. Cohan RH, Saeed M, Schwab SJ, et al. Povidone-iodine sclerosis of pelvic 
lymphoceles: a prospective study. Urol Radiol1988;10:203-6.

7. Montalvo BM, Yrizarry JM, Casillas VJ, et al. Percutaneous sclerotherapy of lymphoceles related to renal transplantation. $\mathbf{J}$ Vasc Interv Radiol1996;7:117-23.

8. Schutz R, Delclaux C, Balloul-Delclaux E, et al. Traitement des pyothorax et pyopneumothorax d'origine infectieuse d'évolution chronique par drainage-lavage à la polyvinylpyrrolidone iodée. Rev Mal Respir1992;9:313-17.

9. Echavarria A, Pinzon V, Bares JP, et al. Intracavitary treatment of malignant pleural effusion with iodine-povidone. Rev Med Panama1991;16:69-74.

10. Buttiker, V., S. Fanconi, and R. Burger, Chylothorax in children: guidelines for diagnosis and management. Chest, 1999. 116(3): p. 682-7.

11. Blalock A, Cunningham RS, Robinson CS: Experimental production of chylothorax by occlusion of the superior vena cava. Ann Surg 1936;104:359-364.

12. Szabo G, Magyar Z: Effect of increased systemic venous pressure on lymph pressure and flow. Am J Physiol 1967;212:1469-1974.

13. Liu, J., et al., Ultrasound-guided intranodal lipiodol lymphangiography from the groin is useful for assessment and treatment of post-esophagectomy chylothorax in three cases. Int J Surg Case Rep, 2016. 29: p. 103-107.

14. Brissaud O, Desfrere L, Mohsen R, Fayon M, Demarquez JL. Congenital idiopathic chylothorax in neonates: chemical pleurodesis with povidone-iodine. Arch Dis Child Fetal Noenatal 2003;88: F531F533.

15. Mitanchez D, Walter-Nicolet E, Salomen R, Bavoux F,Hubert P. Congenital chylothorax: What is the best strategy?
Arch Dis Child Fetal Noenatal 2006; 91: F153-F154

16. De Beer HGJ, Molet MJT, Janssen JP. Chylothorax. Neth J Med2000;56:25-31.

17. Cohan RH, Saeed M, Schwab SJ, et al. Povidone-iodine sclerosis of pelvic lymphoceles: a prospective study. Urol Radiol 1988;10:203-6

18. Montalvo BM, Yrizarry JM, Casillas VJ, et al. Percutaneous sclerotherapy of lymphoceles related to renal transplantation. J Vasc Interv Radiol 1996;7:117-23.

19. Schutz R, Delclaux C, Balloul-Delclaux E, et al. Traitement des pyothorax et pyopneumothorax d'origine infectieuse d'e'volution chronique par drainagelavage a' la polyvinylpyrrolidone iode'e. Rev Mal Respir1992;9:313-17.

20. Echavarria A, Pinzon V, Bares JP, et al. Intracavitary treatment of malignant pleural effusion with iodine-povidone. Rev Med Panama 1991;16:69-74.

21. KovacikovaL, KunovskyP, LakomyM, SkrakP, MisikovaZ, SimanJ, KostalovaLE. Thyroid hormone status after cardiac surgery in infants with delayed sternal closure and continued use of cutaneous povidone-iodine, Endocr Regul, 2003, vol. 37(pg. 3-9)

22. BryantWP, ZimmermanD. Iodine-induced hyperthyroidism in a newborn, Pediatrics, 1995, vol. 95(pg. 434-436)

23. Olivares-Torres CA, Laniado-LaborinR, Chavez-GarciaC, Leon-GastelumC, Reyes-EscamillA A LightRW. Iodopovidone pleurodesis for pleural effusions, Chest, 2002, vol. 122(pg. 581583). 